\title{
Modal shift for New Zealand shippers for various policy scenarios
}

\section{Hyun Chan Kim, Diana Kusumastuti \& Alan Nicholson}

To cite this article: Hyun Chan Kim, Diana Kusumastuti \& Alan Nicholson (2017): Modal shift for New Zealand shippers for various policy scenarios, New Zealand Economic Papers, DOI: 10.1080/00779954.2017.1359659

To link to this article: https://doi.org/10.1080/00779954.2017.1359659

曲 Published online: 31 Jul 2017.

Submit your article to this journal $₫$

Џ Article views: 29

Q View related articles $₫$

View Crossmark data \lceil 


\title{
Modal shift for New Zealand shippers for various policy scenarios
}

\author{
Hyun Chan Kim ${ }^{\mathrm{a}}$, Diana Kusumastuti ${ }^{\mathrm{b}}$ and Alan Nicholson ${ }^{\mathrm{b}}$ \\ ${ }^{a}$ Waikato Institute of Technology, Centre for Engineering and Industrial Design, Hamilton, New Zealand; ${ }^{\mathrm{b}}$ Civil and \\ Natural Resources Engineering, University of Canterbury, Christchurch, New Zealand
}

\begin{abstract}
Increasing transport problems caused by high dependency on road transport, has brought us to investigate various policy scenarios to promote a greater use of rail and coastal transport for freight transport in New Zealand. For this, we examined how factors associated with freight transport (e.g. cost and reliability) influenced the transport decisions of shippers with various operation types. Online stated preference surveys were developed and mixed-logit models were estimated from the data provided by 233 shippers. These models were used to calculate the base mode shares, and subsequently, to test various hypothetical policy options for promoting greater use of rail and coastal transport. The results show that a substantial improvement in reliability of both the rail and coastal freight transport services will lead to a substantial decline in the share of road transport, especially for shippers with short-haul and longhaul operations, transporting either large or small shipment volume.
\end{abstract}

ARTICLE HISTORY

Received 9 April 2017

Accepted 21 July 2017

\section{KEYWORDS}

Policy scenarios; modal shift; mixed-logit model; stated preference; New Zealand shippers

\section{Introduction}

Growing concern about road congestion and road safety, and increasing awareness about global climate change, have brought attention to freight transportation, particularly road freight transport. It is often argued that there is a need to introduce innovative policies and technologies for reducing the dependency on road freight transport. Shippers and logistics service providers naturally focus on the logistics trade-offs, especially the trade-off between transport cost and transport time. Market forces have increased the demand for reliable, flexible, cost-effective, timely and viable door-to-door freight services within New Zealand.

Freight transport demand (tonne-km) in New Zealand grew by more than $32 \%$ during the period from 1995 to 2005, and was predicted to grow about 70\% between 2005 and 2020 (Richard Paling Consulting, 2008). However, a more recent study (Deloitte, 2014) found that freight transport demand (tonne-km) decreased by $2 \%$ between 2006/2007 and 2012, despite there being a 5\% increase in the tonnage, indicating a trend towards shorter movement lengths. Deloitte (2014) predicted a 58\% increase in tonnage, and a 48\% increase in tonne-km, between 2012 and 2042, implying a continuation of the trend towards shorter movement lengths.

Most freight movements in New Zealand are by road transport, which in 2012 accounted for $91.4 \%$ of tonnage and $70.3 \%$ of tonne-km, with the average movement length being $86 \mathrm{~km}$ (Deloitte, 2014). It was also found that rail accounted for only $6.8 \%$ of tonnage, but the greater average movement length $(260 \mathrm{~km})$ meant that it accounted for $16.0 \%$ of tonne-km. While coastal shipping accounted for only $1.8 \%$ of tonnage, the even longer average movement length $(837 \mathrm{~km})$ meant that it accounted for $13.7 \%$ of the tonne-km. 
New Zealand's road system consists of a State Highway network, with about 11,200 km of major roads and motorways, but this is only about $12 \%$ of the total length of all roads (Ministry of Transport, 2012). The great majority of the freight movements are handled by roads in the Auckland, Waikato, Bay of Plenty, Wellington and Canterbury regions (especially in the main cities in those regions), and $19 \%$ of the tonne-kms occur on just $6.5 \%$ of the State Highway network, i.e. the 'highvolume highways' (Ministry of Transport, 2012).

There are about $4,000 \mathrm{~km}$ of railway, and rail is an important mode of transport for general cargo in containers over long distances. The most utilized segments of the network are in the Auckland, Waikato and Bay of Plenty regions, and between Christchurch and both the West Coast and Picton.

Despite the effort of the government to re-purchase rail infrastructure and deregulate operations, New Zealand rail has struggled due to the following reasons: (a) customers who cannot meet the minimum loading size by rail are shifting to trucking, making rail dependent on a small group of larger companies; (b) the starting rate for less-than-wagon loads is greater than for trucks; (c) the provision of railway staff and equipment for small contracts is more expensive than providing a truck; and (d) door-to-door shipping does not always suit rail (Rockpoint Corporate Finance, 2009). In addition, New Zealand rail has infrastructural network constraints, limited load capacity and limited double-tracked sections, speed restrictions and low height clearances, making it more difficult to attract potential customers (Rockpoint Corporate Finance, 2009).

New Zealand's sea transport is currently serviced by twelve key ports, including ten ports providing container terminals and cranes for domestic and international trade (Rockpoint Corporate Finance, 2009). In the 2006/2007 financial year, coastal shipping (both international and domestic shipping lines) carried about $15 \%$ of the tonne-kms of domestic freight. Despite this low market share, Rockpoint Corporate Finance (2009) emphasised that coastal shipping has good potential for growth, especially for transporting retail and manufactured products between distribution centres on the Auckland to Christchurch route, where coastal shipping had an estimated $38 \%$ share of the total volume.

There have been a number of studies (i.e. Bolland, Weir, \& Vincent, 2005; Deloitte, 2014; Richard Paling Consulting, 2008; Rockpoint Corporate Finance, 2009; Warwick Walbran Consulting, 2010) which have shed some light on the causes of the low market shares for rail and coastal shipping. However, none of those studies investigated the underlying behaviour of the individual firms who actually make freight mode choice decisions, or examined in detail the factors that influence those decisions.

Bolland et al. (2005) developed the New Zealand National Freight Matrix for long distance and high tonnage movements of major commodities in the base year of 2002 by surveying freight consignors. However, only 35 companies and organizations provided full or partial details. Given the small sample size, along with the fact that the study focused on inter-regional freight movements, it was not possible to draw conclusions for the entire national freight transport market.

The first comprehensive freight movement study in New Zealand was the National Freight Demand Study (Richard Paling Consulting, 2008) for the Ministry of Transport. This study investigated the movements of thirteen key commodities (e.g. milk/dairy, wood, meat, horticulture, aggregate minerals and some bulk products) by interviewing and surveying around 100 key firms and individuals across various industries. The study identified the supply chains of key industries, summarized the distribution patterns of those selected commodities, and estimated the nationwide origin-destination $(\mathrm{O} / \mathrm{D})$ matrix on the basis of commodities and modes of transport (i.e. road, rail and coastal shipping). The study identified that, in general, freight mode choice was influenced by cost, reliability, modal connectivity, restitutions (damage and loss), mode-to-mode transfer, customer services, environmental and sustainability issues, and some logistics issues within the supply chain. It was found that freight mode choice was also influenced by the inherent value of goods being transported. For low value goods, the cost of transport was a major consideration whilst for high value goods, reliability and security of delivery were considered much more important factors. Unfortunately, the study addressed only those factors qualitatively and thus, it was not possible to estimate the relative importance of the factors. 
A study by Rockpoint Corporate Finance (2009) provided a better understanding of how New Zealand shippers choose the appropriate freight mode of transport. Data were collected by interviewing 45 firms across various industries. The study included five freight mode factors, namely product care, cost, timeliness, reliability and safety. Reliability was cited as the most important factor, followed by product care and safety. Interestingly, in this study, 'reliability' and 'timeliness' were regarded as two separate factors. Timeliness often encompasses both the average shipment time and the variability in shipment time (Evers, Harper, \& Needham, 1996). Rockpoint Corporate Finance (2009) also noted that low market shares for rail and coastal shipping in New Zealand were due to long delivery times and limited service frequency. For example, the approximate delivery times from Auckland to Christchurch were estimated to be 24 hours by truck, 36 hours by trains and 40 hours by ship.

A study of mode choice factors in the forestry industry in the Gisborne region was conducted by Warwick Walbran Consulting (2010). The study entailed interviewing the employees of large forestry companies and exporters, and concluded that price is the most important factor that influences those firms' freight transport mode choice.

The second National Freight Demand Study (Deloitte, 2014) used a similar approach to that used by Richard Paling Consulting (2008) and found that the factors affecting mode choice were much the same as found in the first National Freight Demand Study. Again, it was not possible to estimate the relative importance of the factors.

The results of international studies largely confirm the findings of the New Zealand studies. For instance studies by Daughety (1979), Fowkes and Tweddle (1988), and Widlert and Bradley (1992) found that freight transport factors, such as transportation cost, transit time, frequency, and damage rates, were the principal explanatory variables. However, only a few international studies have attempted to systematically establish a relationship between mode choice and firms' characteristics (Gunn, 2002; Jiang, Johnson, \& Calzada, 1999; Rich, Holmblad, \& Hansen, 2009). This may be because of the difficulty in collecting the necessary data, for instance due to the great heterogeneity of firms and issues related to confidentiality and reliability of data (Ortúzar \& Willumsen, 2001). As a result, the influence of firms' characteristics on freight mode choice is not well understood.

If mode choice is to be changed, it is crucial to understand the relative importance of factors that influence the freight mode choice decisions of shippers and freight service providers, taking into account firms' characteristics and their typical shipment operation type (e.g. distance, size and value of products). Such knowledge can be used to identify policies that can effectively reduce the dependency of freight transport on roads and promote the use of other modes (i.e. rail and coastal shipping). Hence, this study aimed to address the above issues, by developing choice models, which include transport mode and shipper characteristics, and to use these models to test the implications of various hypothetical policy scenarios for encouraging a mode shift from road to rail or to coastal shipping.

To the best of the authors' knowledge, the only New Zealand studies that attempted to investigate the underlying behaviour of shippers and factors that influence their freight mode choice decisions were those by Kim and Nicholson (2013), Kim, Nicholson, and Kusumastuti (2014), and Kim, Nicholson, and Kusumastuti (2017). These studies used datasets collected using online stated preference surveys (described below) and an online revealed preference survey (Kim, 2014).

Kim et al. (2014) used the revealed preference data and ranking data of the importance of preselected factors (i.e. timeliness, cost, customer service, accessibility, suitability and damage) to identify perceived constraints on modal shift from road to rail or coastal shipping by New Zealand freight shippers, using the ranked-ordered logit method. The study identified timeliness followed by accessibility as the highest modal shift constraints for shifting from road to rail. However, accessibility was perceived by shippers as a higher constraint than timeliness when considering shifting from road to coastal shipping. The study also identified some relationship between firms' logistic characteristics and shippers' rank ordering of constraints, with firms' lead time policy being the greatest influence.

Kim et al. (2017) aimed to identify 'unobservable' subgroups of shippers with long-haul operations, and how the weights of factors differ across the subgroups. They employed a model-based clustering approach named the latent class modelling technique, using a dataset collected from the 
stated preference surveys. In the study, the differences, in terms of model-fit statistics and parameter coefficients, between latent class multinomial logit and mixed-logit models were further investigated. The results suggest the presence of classes (or subgroups) within long-haul shippers with distinct preferences, highlighting heterogeneity of shippers having the same types of shipping operations.

As previous stated, this study aims to assess how various hypothetical policy scenarios for encouraging a mode shift from road to rail or to coastal shipping would perform. Thus, it has a different focus than the previously mentioned studies (i.e. Kim et al., 2014, 2017). This study expands a previous study by Kim and Nicholson (2013). The main difference between the previous study and this study is the former placed more emphasis on comparing the coefficients of multinomial and mixed-logit models, and used the multinomial logit model to estimate mode shares. Furthermore, it analysed only data for shippers with long-haul operations.

In this study, shippers or freight service providers with four types of shipment operation, i.e. long-haul with full container load, long-haul with less-than-a container load, short-haul with full container load, and short-haul with less-than-a container load, were targeted. Data from four online stated preference surveys, each of which targeted shippers or freight service providers with a particular type of shipment operation, were used to estimate the coefficients of mixed-logit models. 233 shippers and freight service providers participated in the surveys, leading to a total of 4194 observations. The selected models were then used to test various hypothetical policy scenarios relevant to New Zealand freight transport.

The remainder of this paper is structured as follow. First, mixed-logit modelling and the stated preference survey design will be described in turn. The sample will then be described. The results of mixed-logit modelling and the policy implications of various policy scenarios will then be presented and discussed. Finally, conclusions will be drawn.

\section{Mixed-logit modelling}

The mixed-logit model is a type of discrete choice model that allows the coefficients of observed variables to vary randomly between people, making it a more realistic representation of choice behaviour than the well-known multinomial logit model with 'fixed' coefficients. The mixed-logit model also allows the stochastic component to be correlated over alternatives. This makes the model more realistic as unobserved information relevant to making a choice may in reality induce correlation across the transport mode alternatives. Thus, the stochastic element in the model consists of two parts. One part is allowed to be correlated over alternatives and is heteroscedastic, and the other part is independently and identically distributed (IID) over alternatives and individuals, as shown below.

$$
U_{i j}=\left(\beta+\vartheta_{i j}\right) X_{i j}+\varepsilon_{i j}
$$

where $U_{i j}$ is the true utility of alternative $j$ by shipper $i, X_{i j}$ is the observed variables and is related to shipper $i$ and alternative $j, \beta$ is a vector of coefficients, $\varepsilon_{i j}$ is a random term (with zero mean) that is IID over alternatives and individuals, and $\vartheta_{i j}$ is an error component that can be correlated among alternatives and heteroscedastic for each individual.

The mixed-logit model assumes a general distribution for $\vartheta_{i j}$ (e.g. normal, log-normal, triangular or uniform) and an IID Gumbel distribution for $\varepsilon_{i j}$ (Hensher \& Greene, 2003). The density function of the error component $\vartheta_{i j}$ is denoted by $f\left(\vartheta_{i j} \mid \tau\right)$, where $\tau$ is a parameter vector of the distribution of $\vartheta_{i j}$. The conditional probability of choosing alternative $j$ given the value of component $\vartheta_{i j}$ is:

$$
Q_{i}\left(j \mid \vartheta_{i j}\right)=\frac{\exp \left(x_{i j} \beta+\vartheta_{i j}\right)}{\sum_{k \in Z_{i}}^{J} \exp \left(x_{i k} \beta+\vartheta_{i j}\right)}
$$


Since $\vartheta_{i j}$ is not given, the unconditional choice probability is the integral of the conditional choice probability, $Q_{i}\left(j \mid \vartheta_{i j}\right)$, over the distribution of $\vartheta_{i j}$. This model is called the mixed-logit model because the choice probability is a mixture of logits with $f\left(\vartheta_{i j} \mid \tau\right)$ as the mixing distribution (Hensher, Rose, \& Greene, 2005). In general, the mixed-logit model uses simulated maximum likelihood estimation for computing the approximate probability (McFadden \& Train, 2000).

For simulation purposes, the error component is assumed to have a specific structure, by allowing the individual parameter estimates $\vartheta_{i j}$ in the vector $\vartheta$ to be defined as follows:

$$
\vartheta_{i j}=\vartheta_{j}+\sigma_{j} \varphi_{i j}
$$

where $\varphi_{i j}$ is the individual specific heterogeneity with mean zero and standard deviation equal to one, $\sigma_{j}$ is the standard deviation of the distribution of $\vartheta_{i j}$ around $\vartheta_{j}$, and $\vartheta_{j}$ is the population mean.

\section{Stated preference survey}

The data used in this study were collected from four stated preference surveys. The structure of these surveys as well as the alternatives, attributes and attribute levels used will be described in turn. Note that the sample size and the firms' characteristics and logistic operations will be described in the next section.

\subsection{Structure of the survey}

Before conducting the stated preference surveys, managers, directors or owners of potential firms and transport logistics services were contacted and asked to participate in a pilot survey using the revealed preference method. In this pilot survey, shippers were asked to describe their freight transport patterns, in terms of business types, size of shipments and their usual freight transport mode choice. Based on their responses, the participants were assigned to one of the four predefined groups:

- the long-haul (i.e. interisland) and full container load (FCL) shippers (Choice Experiment Set/ CES1);

- the short-haul (within city, region or island) and FCL shippers (CES2);

- the long-haul and less-than-a container load (LCL) shippers (CES3);

- the short-haul and LCL shippers (CES 4).

Note that in the survey, the FCL was represented by a 20 -foot container (20 feet long, 8 feet tall) and it can typically hold between 9 and 11 pallets. The LCL was represented by shipment of around 5 pallets.

Based on those groups, each of the respondents were assigned eighteen hypothetical questions (or choice tasks) developed using orthogonal design principles. These questions were formed by varying the levels of preselected attributes and they were designed in such a way as to reflect the respondents' real situations as closely as possible (e.g. with regard to transport time and cost).

Note that many researchers (e.g. Bliemer, Rose, \& Hensher, 2009; Huber \& Zwerina, 1996; Kessels, Jones, \& Goos, 2011; Sándor \& Wedel, 2002) argued that efficient design, another type of experimental design besides orthogonal design, is, in fact, better for choice studies. Orthogonal design aims to minimize correlations between attribute levels whereas efficient design aims to minimize the standard errors of parameter estimates. One of the main drawbacks of using orthogonal design for choice studies is because non-design data (e.g. the socio-demographic characteristics of participants) are typically analysed together with experimental design data and this will most likely produce some correlations (Bliemer \& Rose, 2009). Using an efficient design is therefore considered more 
beneficial because such a design ensures more reliable parameter estimates with smaller sample sizes (Huber \& Zwerina, 1996). However, an efficient design is more difficult to generate, requiring specialized software (e.g. NGENE by ChoiceMetrics Pty. Ltd., n.d.). On the other hand, orthogonal design is convenient to use because several tables of orthogonal arrays have been mathematically derived for a number of attributes and levels (e.g. Addelman, 1962; Eccleston \& John, 1996; Hedayat, Sloane, \& Stufken, 1999). Considering the strengths and weaknesses of both design methods, it was decided to use orthogonal design in this study.

Before the choice tasks, a hypothetical situation was given to the respondents. The respondents in CES1 and CES 3 (i.e. the long-haul operations) were asked to imagine a situation in which they need to transport either FCL valued $\$ 20,000$ (for CES1) or LCL valued $\$ 5000$ (for CES3) between the North and South Islands, e.g. from their firm in Auckland to their customer in Christchurch. The respondents in CES2 and CES4 (i.e. the short-haul operations) were asked to imagine a situation in which they need to transport either FCL valued $\$ 20,000$ (for CES2) or LCL valued $\$ 5,000$ (for CES4) within an island, e.g. from their firm in Auckland to their customer in Hamilton.

Besides the choice tasks, the respondents were also asked to describe their business characteristics, such as the number of employees, the size of firm, the product shelf life, the export volume, the transport distance, accessibility to rail and seaports, the number of owned trucks, and the number and length of contracts with a transport service provider.

\subsection{Alternatives}

For each choice task, the respondents were asked to choose between three alternatives. For the respondents in CES1, the three alternatives were road (the base alternative, which will be described below), rail, and sea transport. For those in CES2, 3 and 4, the three alternatives were rail and two options of road transport, i.e. owned-fleet (the base alternative) and for-hire carrier.

As shown above, one alternative was set as a base alternative, representing the participants' usual transport choice. These base alternatives were selected based on the results of a pilot study using the revealed preference method. The base alternative gave the respondents an option to choose from when the conditions related to the other alternatives were not considered attractive, making the choice decision more realistic. In fact, many choice studies that include the base option assume that the reason behind its selection is the unattractiveness of the other alternatives. This is of course a bold assumption, as there are other reasons for opting for the base option, such as respondents' resistance to change, fatigue, learning effect, and the complexity of the choice tasks. Despites these disadvantages, Hanley, Mourato, and Wright (2001) and Lanz and Provins (2012) stated that the base alternative can make results more consistent and reflect economic preferences. In this study, the base option was included to allow us to investigate the attractiveness of the attribute levels of the other competing alternatives, showing when the respondents moved from the base alternative.

\subsection{Attributes and levels}

The results of a range of empirical studies on freight mode choice (Evers et al., 1996; Gilmour, 1976; McGinnis, 1990; Murphy \& Daley, 1994; Murphy \& Hall, 1995) suggest that the transport mode decision is typically affected by transport cost, time and reliability. Furthermore, the results of freight studies conducted in New Zealand (e.g. Richard Paling Consulting, 2008; Rockpoint Corporate Finance, 2009) conclude that the key factors that influence shippers' freight mode choice are timeliness and cost. The results of a study by Kim et al., 2014 show that the low service frequencies of rail and coastal shipping were more often mentioned as discouraging factors by freight agents than by shippers. Additionally, the results of a study by Kim and Nicholson (2013) also show that New Zealand shippers have some negative perceptions towards transporting goods by rail transport rather than by truck, because of the increased risk of loss or damage for rail transport. Hence, the attributes selected in this study were transport cost, time, (on-time) reliability and the risk of loss or damage 
Table 1. Attributes and levels used in the surveys.

\begin{tabular}{|c|c|c|c|}
\hline CES 1 & & & \\
\hline Transport options & By truck (The base option) & By sea & By rail \\
\hline \multirow{3}{*}{ Price } & $\$ 3766$ & $\$ 1534$ & $\$ 2135$ \\
\hline & & $\$ 1704$ & $\$ 2372$ \\
\hline & & $\$ 1874$ & $\$ 2609$ \\
\hline Transport Time & $24 \mathrm{hrs}$ & $72,84,96 \mathrm{hrs}$ & $36,48,60 \mathrm{hrs}$ \\
\hline On-time Reliability & $100 \%$ & $80,85,90 \%$ & $85,90,95 \%$ \\
\hline Service Frequency & - & 5,7 per week & 2, 4 per day \\
\hline \multicolumn{4}{|l|}{ CES $2,3,4$} \\
\hline Transport options & By owned truck (The base option) & By for-hire truck & By rail \\
\hline \multirow[t]{9}{*}{ Price } & SET2: $\$ 3200$ & $\$ 2572$ & $\$ 2462$ \\
\hline & & $\$ 2858$ & $\$ 2735$ \\
\hline & & $\$ 3144$ & $\$ 3009$ \\
\hline & SET3: \$1469 & $\$ 1181$ & $\$ 1130$ \\
\hline & & $\$ 1312$ & $\$ 1255$ \\
\hline & & $\$ 1443$ & $\$ 1381$ \\
\hline & SET4: \$1115 & $\$ 896$ & $\$ 858$ \\
\hline & & $\$ 996$ & $\$ 953$ \\
\hline & & $\$ 1096$ & $\$ 1048$ \\
\hline \multirow[t]{3}{*}{ Transport Time } & SET2: $18 \mathrm{hrs}$ & $36,48,60 \mathrm{hrs}$ & $60,72,84 \mathrm{hrs}$ \\
\hline & SET3: $36 \mathrm{hrs}$ & $48,60,72 \mathrm{hrs}$ & $72,84,96 \mathrm{hrs}$ \\
\hline & SET4: $18 \mathrm{hrs}$ & $36,48,60 \mathrm{hrs}$ & $60,72,84 \mathrm{hrs}$ \\
\hline On-time Reliability & $100 \%$ & $90,95,100 \%$ & $85,90,95 \%$ \\
\hline Risk of Damage \& Loss & Less than $5 \%$ & Less than $5 \%$ & Less than $5 \%$ \\
\hline & & & More than $5 \%$ \\
\hline Service Frequency & - & - & 2, 4 per day \\
\hline
\end{tabular}

for all modes, and service frequency for rail and coastal transport, as will be detailed below and summarized in Table 1.

\subsubsection{Transport cost}

In a firm's logistics operation, transport cost is one of the largest components of the total logistics cost and it is one of the most important factors that influence shippers' freight mode decisions. However, it was rather difficult to decide on the levels of this attribute. Transport service providers that were contacted were reluctant to provide information about transport rates because of the confidentiality and sensitivity of such information and the competitive nature of the businesses. In addition, transport rates varied considerably between carriers or transport service providers and were also affected by volume discounts and the length of contracts. In the end, price quotes (excluding GST and discount, and including door-to-door service for road) were obtained from two road transport carriers and the railway company (Kiwi Rail Ltd.). The rail costs for LCL shipments were later recalculated using a linear relationship based on the cost per tonne-km, as described in Ballou (2004). Furthermore, the transport cost for the coastal shipping was based upon the Freight Charge Comparison Report done by Pacific Logistic Ltd. (2011) for the Ministry of Transport.

The final estimated transport costs for the road, rail and sea alternatives were set as the base level of cost. The attributes of transport cost were assigned three levels (low, medium, and high) with the medium cost being the base level and the higher and lower costs in turn being $10 \%$ higher and lower than the base level (Table 1).

\subsubsection{Transport time}

Transport time is an important factor influencing freight mode choice, especially for manufacturers and wholesalers that may offer fast delivery options as a part of their value proposition (Rockpoint Corporate Finance, 2009). As noted in the first National Freight Demand Study (Richard Paling Consulting, 2008), a shipper's decision to use coastal shipping or rail is often constrained by transport time. 
In the stated preference surveys, transport time (in hours) was expressed as a range, with a midrange 'typical' value, and upper and lower bounds. The mid-range value of transport time was calculated using the same process for assigning transport cost. To minimise the variation in the total transport time for rail and coastal shipping, a minimum transfer time and road transport time was used. Furthermore, all the services in the choice tasks were assumed to be door-to-door. Based on existing services, the transport time for each mode between Auckland and Christchurch was estimated to be 24 hours, 36 hours and 40 hours for road, rail and sea transport alternatives in turn (Rockpoint Corporate Finance, 2009).

\subsubsection{On-time reliability}

In the study by the Rockpoint Corporate Finance (2009), reliability was cited as the most important factor that influences shippers' freight mode decisions. The term 'reliability' within a transport context has quite a broad spectrum of meanings. In this study, reliability was defined as the probability of arriving within a given time. The attribute level was set as $100 \%$ for truck whereas the three attribute levels were $85 \%, 90 \%$ and $95 \%$ for rail and $80 \%, 85 \%$ and $90 \%$ for coastal shipping. These levels were assigned based on comments from industry experts consulted before conducting the surveys and these levels reflect the fact that rail and coastal shipping are currently having lower rates of ontime performance.

\subsubsection{Risk of damage and loss}

The study by Rockpoint Corporate Finance (2009) found that shippers ranked product care as the second most important factor that influences freight mode choice. Similarly, the first National Freight Demand Study (Richard Paling Consulting, 2008) stated that security and potential damage to the product is a considerably important attribute, particularly if a shipper is considering transporting goods via rail or coastal shipping. Based on the discussions with industry experts, two levels were assigned to the attribute of risk of damage or loss, i.e. less than $5 \%$ and over $5 \%$ of the volume being stolen or damaged.

\subsubsection{Service frequency}

The attribute of service frequency was relevant only to the rail and sea transport alternatives. Based on the frequency of existing rail and shipping services, two levels were assigned to this attribute, i.e. two and four services per day for rail, and five and seven services per week for sea transport.

\section{Description of the sample}

The call for participants was sent through email to 2,099 shippers and freight agents in New Zealand (i.e. managers, directors or owners) in the mid/end of 2012. Two reminder emails were sent subsequently within a two week period. 272 shippers and freight agents participated in the survey. However, due to incomplete responses, data from only 233 shippers and freight agents (leading to a total number of 4,194 observations) could be used for further analysis.

Amongst the 233 respondents, about 55\% of them indicated that their firm is a small and medium enterprise (SME) with 19 or less employees. However, six firms have over 500 employees. $44 \%$ of the respondents were manufacturers, $21 \%$ were wholesalers and retailers, $19 \%$ were primary and raw material providers, and $16 \%$ were freight agents and logistics firms, including warehousing and transport. With respect to product shelf life, nearly $70 \%$ of the respondents indicated that their products have more than a year of shelf life.

46 respondents (i.e. 828 observations) were categorized as long-haul and FCL shippers (CES1), 15 respondents (i.e. 270 observations) were categorized as short-haul and FCL shippers (CES2), 144 respondents (i.e. 2,592 observations) were categorized as long-haul and LCL shippers (CES3), and 28 respondents (i.e. 504 observations) were categorized as short-haul and LCL shippers (CES4). It can be seen that long-haul and LCL shippers (CES3) dominated the sample (i.e. 62\%). 


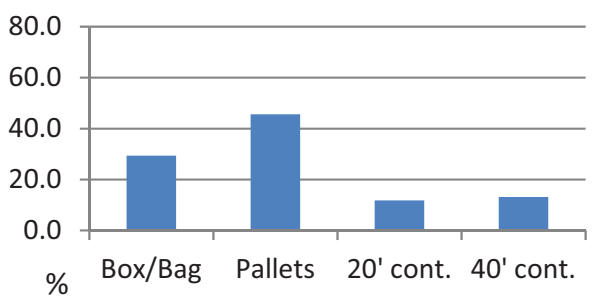

(a) Size of shipment

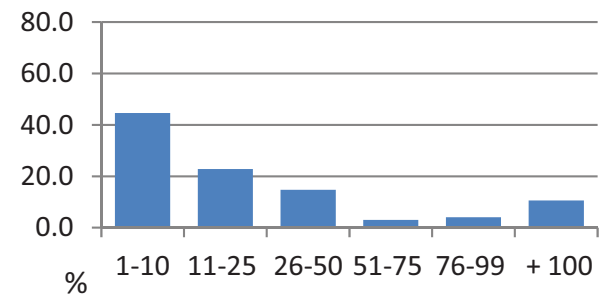

(c) Distance to rail-head $(\mathrm{Km})$

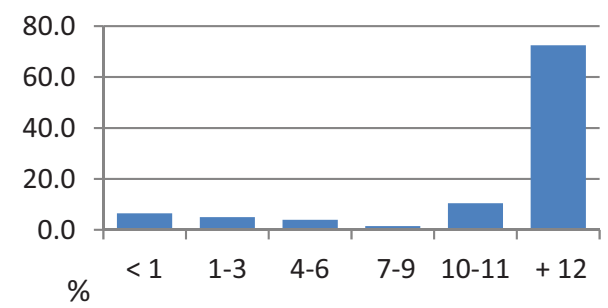

(e) Average shelf life of products (Months)

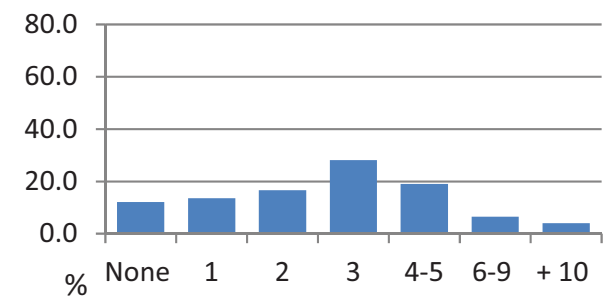

(g) Number of Transport Service Providers (TSP)

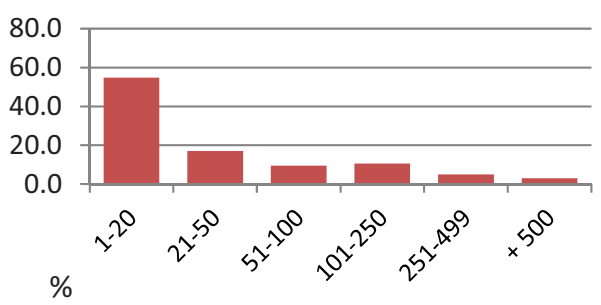

(b) Number of employees (\%)

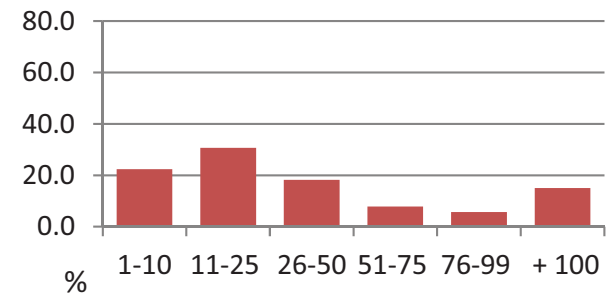

(d) Distance to sea-port (Km)

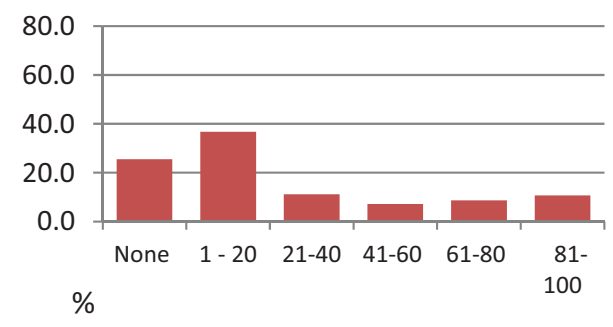

(f) Average export volume (\%/year)

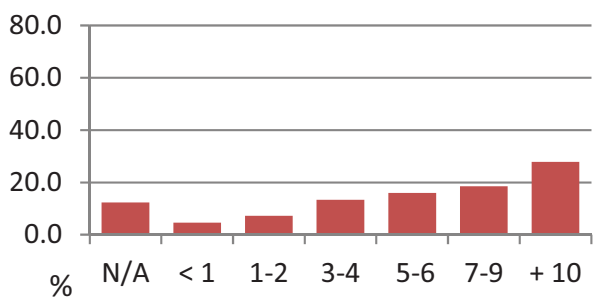

(h) Average contract length of TSP (year)

Figure 1. Description of the sample.

Furthermore, $78 \%$ of the respondents stated that they distribute goods all over the country, $17 \%$ distribute within an island, and only $5 \%$ distribute within a region or city. Additionally, $75 \%$ of the respondents indicated that their shipment size is less than four tonnes and nearly $46 \%$ stated that they transport only pallet size shipments. Both figures reflect the typically low shipment sizes for manufacturers and wholesalers/retailers (i.e. the majority of respondents) compared to primary/raw material providers. Further information regarding the sample can be seen in Figure 1.

\section{Results of mixed-logit modelling}

Before conducting the analysis, the data were coded using a coding scheme presented in Table 2. Subsequently, mixed-logit models were estimated using the NLOGIT software. Note that other models were estimated using more sophisticated modelling techniques (e.g. generalized mixed-logit 
Table 2. Coding scheme.

\begin{tabular}{|c|c|c|}
\hline Attributes & Definition & Unit \\
\hline \multicolumn{3}{|c|}{ Attributes of the transport mode alternatives } \\
\hline COST & Door to Door transportation cost & $\$ N Z$ \\
\hline TIME & Door to Door transportation time & Hour \\
\hline RELIAB & $\begin{array}{l}\text { Ontime reliability (the probability of arriving within a given transport time): } \\
\text { CES1: } 5 \text { level effect coding }(-3,-1,0,+1,+3) \\
\text { CES2, 3, 4: } 4 \text { level effect coding }(-3,-1,+1,+3)\end{array}$ & $\%$ \\
\hline FREQ & $\begin{array}{l}\text { Service frequency } \\
\text { CES1: } 5 \text { level effect coding }(-3,-1,0,+1,+3) \\
\text { CES2, 3, 4: } 3 \text { level effect coding }(-1,0,+1)\end{array}$ & \#/Day \\
\hline DAMG & $\begin{array}{l}\text { Risk of damage and loss } \\
2 \text { level effect coding }(-1,+1)\end{array}$ & $\%$ \\
\hline \multicolumn{3}{|c|}{ Socio-economic attributes } \\
\hline NEMP & $\begin{array}{l}\text { Number of employee } \\
\begin{array}{l}1=\text { A company has less than } 19 \text { employees (i.e. SMEs) } \\
0=\text { Over } 20 \text { employees }\end{array}\end{array}$ & Person \\
\hline NTRUCK & $\begin{array}{l}\text { Number of truck } \\
\begin{array}{l}1 \\
=\text { No owned truck } \\
0=\text { Has at least one owned truck }\end{array}\end{array}$ & Number \\
\hline SLIFE & $\begin{array}{l}\text { Shelf life of products } \\
\qquad \begin{array}{l}1=\text { Average shelf life of products less than } 12 \text { months } \\
0=\text { Product shelf life more than } 12 \text { months }\end{array}\end{array}$ & Month \\
\hline EVOL & $\begin{array}{l}\text { Percentage of exports } \\
1=\text { Domestic only (No export in 2011) } \\
0=\text { Exports any volume of its production in } 2011\end{array}$ & $\% /$ year \\
\hline NTSP & $\begin{array}{l}\text { Number of Transport Survice Providers (TSP) } \\
\begin{array}{l}1=\text { A company has less than } 5 \text { contracts with TSPs } \\
0=\text { A company has over } 5 \text { contracts with TSPs }\end{array}\end{array}$ & Number \\
\hline LTSP & $\begin{array}{l}\text { Agerage Length of contract with TSP } \\
\begin{aligned} 1 & =\text { Length of contract with transport carriers not exceeding } 3 \text { years } \\
0 & =\text { Over } 3 \text { years }\end{aligned}\end{array}$ & Year \\
\hline DTORAIL & $\begin{array}{l}\text { Distance to railhead } \\
\begin{array}{l}1=\text { Distance to railhead less than } 25 \mathrm{~km} \\
0=\text { Distance to railhead over } 25 \mathrm{~km}\end{array}\end{array}$ & $\mathrm{Km}$ \\
\hline \multicolumn{3}{|c|}{ Non-attribute Variable } \\
\hline ASC & $\begin{array}{l}\text { Alternative Specific Constants } \\
\text { CES1: Coastal shipping and Rail }=1 \text {, Road }=0 \\
\text { CES2,3,4: For-hired Carriers and Rail =1, Owned-truck }=0\end{array}$ & \\
\hline
\end{tabular}

model and 'scale heterogeneity' mixed-logit model). However, after comparing the model-fit statistics of those models and the mixed-logit models, and conducting log-likelihood ratio tests, it was decided to use the mixed-logit models, because the statistical fit of the generalized mixed-logit models and 'scale heterogeneity' mixed-logit models were not better than those of the mixed-logit models (for details, see Kim, 2014). The results, i.e. parameter coefficients, standard error of coefficients (SE), standard deviation of random parameter (SD) and model statistics, are presented in Table 3.

Note that a normal distribution was used for all random parameters (except for cost, where a lognormal distribution was used). Several mixed-logit models were initially developed, varying the type of distribution for random parameters. The results show that a mixed-logit model with either a normal or triangular distribution has consistently better model-fit statistics (in terms of the likelihood ratio test and Pseudo $R^{2}$ ) compared with a mixed-logit model with a log-normal distribution. The choice between normal and triangular distributions is partly subjective. Model-fit statistics (e.g. the likelihood ratio and Pseudo $R^{2}$ ) of models with normal and triangular distributions were fairly similar, with model-fit statistics (particularly the log-likelihood ratio) of a model with a normal distribution being slightly better than with a triangular distribution. The signs and magnitudes of each estimated coefficient (and its standard error) show no substantial differences. Because of this, and the fact that a normal distribution is more commonly used, it was decided to use a normal distribution for all non-price-related random parameters. Additionally, to simplify the results, random parameters of the selected model were not allowed to be correlated. It is also acknowledged that 
Table 3. The estimated coefficients of mixed-logit models.

\begin{tabular}{|c|c|c|}
\hline Attributes & Coeff. & SE \\
\hline \multicolumn{3}{|l|}{ a. CES1 } \\
\hline \multicolumn{3}{|c|}{ Random parameters: Mean } \\
\hline TIME & -0.006 & 0.017 \\
\hline FREQ & $0.489^{* *}$ & 0.214 \\
\hline \multicolumn{3}{|c|}{ Non-random parameters } \\
\hline ASCS (Sea) & 2.571 & 2.634 \\
\hline ASCR (Rail) & 0.989 & 2.159 \\
\hline COST & $-0.004^{* * *}$ & 0.001 \\
\hline RELIAB & $0.090^{* * *}$ & 0.026 \\
\hline TIME*NTRUCK & $0.033^{* *}$ & 0.015 \\
\hline ASCS*SLIFE & 0.450 & 1.320 \\
\hline ASCS*NTSP & -1.980 & 2.190 \\
\hline ASCS*EVOL & -1.534 & 2.501 \\
\hline ASCS*LTSP & $1.744^{*}$ & 0.990 \\
\hline ASCR*SLIFE & 1.460 & 1.114 \\
\hline ASCR*NTSP & -1.101 & 1.905 \\
\hline ASCR*EVOL & -0.432 & 1.114 \\
\hline ASCR*LTSP & 1.111 & 0.801 \\
\hline \multicolumn{3}{|c|}{ Random parameters: SD } \\
\hline TIME & $0.129^{* * *}$ & 0.017 \\
\hline FREQ & $0.967^{* * *}$ & 0.127 \\
\hline \multicolumn{3}{|l|}{ Model statistics } \\
\hline Log Likelihood & & -273.15 \\
\hline Pseudo $R^{2}$ & & 0.581 \\
\hline Observations & & 828 \\
\hline \multicolumn{3}{|l|}{ b. CES2 } \\
\hline \multicolumn{3}{|c|}{ Random parameters: Mean } \\
\hline FREQ & 0.180 & 0.163 \\
\hline \multicolumn{3}{|c|}{ Non-random parameters } \\
\hline ASCH (Hired) & $-2.629^{* * *}$ & 0.862 \\
\hline ASCR (Rail) & $-5.354^{* * *}$ & 1.750 \\
\hline COST & $-0.007^{* * *}$ & 0.001 \\
\hline TIME & -0.031 & 0.023 \\
\hline RELIAB & 0.046 & 0.049 \\
\hline DAMG & -0.318 & 0.370 \\
\hline COST*SLIFE & $0.003^{* * *}$ & 0.001 \\
\hline TIME*LTSP & $0.037^{* *}$ & 0.012 \\
\hline \multicolumn{3}{|c|}{ Random parameters: SD } \\
\hline FREQ & $0.308^{* *}$ & 0.142 \\
\hline \multicolumn{3}{|l|}{ Model statistics } \\
\hline Log Likelihood & & -126.04 \\
\hline Pseudo $R^{2}$ & & 0.362 \\
\hline Observations & & 270 \\
\hline \multicolumn{3}{|l|}{ c. CES3 } \\
\hline \multicolumn{3}{|c|}{ Random parameters: Mean } \\
\hline TIME & $-0.051^{* * *}$ & 0.008 \\
\hline FREQ & $0.108^{* *}$ & 0.052 \\
\hline RELIAB & $0.103^{* * *}$ & 0.015 \\
\hline DAMG & $-0.784^{* * *}$ & 0.153 \\
\hline \multicolumn{3}{|c|}{ Non-random parameters } \\
\hline ASCH (Hired) & -0.185 & 0.341 \\
\hline ASCR (Rail) & $-3.082^{* * *}$ & 0.708 \\
\hline COST & $-0.011^{* * *}$ & 0.001 \\
\hline SLIFE & -0.056 & 0.278 \\
\hline $\mathrm{COST}^{*} \mathrm{NEMP}$ & -0.001 & 0.001 \\
\hline COST $*$ LTSP & $-0.006^{* * *}$ & 0.001 \\
\hline FREQ*NEMP & $-0.271^{* * *}$ & 0.086 \\
\hline FREQ*EVOL & $0.158^{*}$ & 0.081 \\
\hline ASCH*NEMP & $0.821^{* * *}$ & 0.277 \\
\hline ASCH*NTRUCK & $0.547^{*}$ & 0.281 \\
\hline ASCR*NTRUCK & 0.164 & 0.489 \\
\hline ASCR*LTSP & $0.905^{* * *}$ & 0.304 \\
\hline ASCR*DTORAIL & 0.268 & 0.307 \\
\hline
\end{tabular}


Table 3. (Continued)

\begin{tabular}{|c|c|c|}
\hline Attributes & Coeff. & SE \\
\hline \multicolumn{3}{|c|}{ Random parameters: SD } \\
\hline TIME & $0.116^{* * *}$ & 0.008 \\
\hline FREQ & $0.225^{* * *}$ & 0.032 \\
\hline DAMG & $1.045^{* * *}$ & 0.103 \\
\hline RELIAB & $0.043^{* * *}$ & 0.014 \\
\hline \multicolumn{3}{|l|}{ Model statistics } \\
\hline Log Likelihood & & -1157.89 \\
\hline Pseudo $R^{2}$ & & 0.491 \\
\hline Observations & & 2592 \\
\hline \multicolumn{3}{|l|}{ d. CES4 } \\
\hline \multicolumn{3}{|c|}{ Random parameters: Mean } \\
\hline FREQ & 0.124 & 0.126 \\
\hline \multicolumn{3}{|c|}{ Non-random parameters } \\
\hline ASCH (Hired) & $-2.227^{* * *}$ & 0.601 \\
\hline ASCR (Rail) & $-3.556^{* * *}$ & 1.297 \\
\hline COST & $-0.018^{* * *}$ & 0.002 \\
\hline TIME & $-0.046^{* * *}$ & 0.013 \\
\hline RELIAB & $0.066^{* *}$ & 0.029 \\
\hline DAMG & -0.149 & 0.308 \\
\hline EVOL & $2.754^{* * *}$ & 0.672 \\
\hline NTSP & $1.183^{* * *}$ & 0.399 \\
\hline LTSP & $-1.534^{* * *}$ & 0.301 \\
\hline $\mathrm{COST}^{*} \mathrm{NEMP}$ & $0.007^{* * *}$ & 0.002 \\
\hline COST*SLIFE & $0.011^{* * *}$ & 0.002 \\
\hline FREQ*NTRUCK & $-0.458^{* * *}$ & 0.144 \\
\hline \multicolumn{3}{|c|}{ Random parameters: SD } \\
\hline FREQ & 0.022 & 0.131 \\
\hline \multicolumn{3}{|l|}{ Model statistics } \\
\hline Log Likelihood & & -231.6 \\
\hline Pseudo $R^{2}$ & & 0.581 \\
\hline Observations & & 504 \\
\hline
\end{tabular}

other means, e.g. marginal effects, can be used to present the results of the study. However, as the main objective of this study was to assess mode shift due to various policy scenarios, the coefficients of the resulted model are only described in general terms.

The results of the CES1 model show that the coefficients of RELIAB and FREQ are positive and statistically significant, implying that shippers seem to favour modes with higher reliability and more frequent services. Note that FREQ is a random parameter and its standard deviation coefficient is also statistically significant. This suggests the existence of heterogeneity in the respondents' preferences for this attribute. Another random parameter in the model is TIME. The mean coefficient of this attribute is not statistically significant but its standard deviation coefficient is significant, again suggesting the existence of heterogeneity in the respondents' preferences for this attribute. The coefficient of COST is statistically significant with a negative sign. This is logical as an increase in transit time is expected to reduce the utility of choosing any freight mode of transport. Note that none of the alternative specific constants (i.e. ASCS and ASCR) are statistically significant. Alternative specific constants (ASCs) capture the mean effects of unobserved factors on utility for each transport alternative. The non-significant ASCs may imply that shippers inherently value the three modes equally.

In terms of socio-economic variables interacting with mode choice attributes in the CES1 model, the attribute of TIME ${ }^{\star}$ TRUCK represents the interaction between TIME and the socio-economic attribute of the number of trucks owned (NTRUCK). This combined attribute shows the possible effect of the interaction between transport time and truck ownership on the utility of choosing a certain mode. The coefficient of this attribute is statistically significant and it has a positive sign. This 
implies that less consideration of transport time is given by shippers that do not own trucks. Additionally, the coefficient of the ASCS ${ }^{\star}$ LTSP attribute is statistically significant with a positive sign, indicating a positive impact of having a long term contact (more than 3 years) on the utility of using sea transport.

The results of the CES2 model show that the coefficient of COST is statistically significant with a negative sign, suggesting a negative influence of an increase in transport cost on the utility of choosing modes. The attribute of FREQ is a random parameter. Its mean coefficient is not statistically significant but its standard deviation coefficient is significant. The coefficients of TIME, RELIAB and DAMG are not statistically significant, even though their signs seem to be logical: increasing travel time and the probability of product damage reduce the utility of choosing modes whilst increasing reliability increases the utility of choosing modes. Note that the coefficients of both ASCH and ASCR are statistically significant and both have a negative sign, with the ASCR having a higher absolute value than ASCH. This means that in general, shippers inherently prefer owned-fleet than forhire and rail carriers, with for-hire carries being preferred more than rail.

In terms of the interaction effects in the CES2 model, the coefficient of COST ${ }^{\star}$ SLIFE is statistically significant with a positive sign. This suggests that shippers that transport products with short shelf lives (i.e. less than 12 months) are less sensitive to the increase of transport cost. This is understandable as products with short shelf lives, such as food and Fast Moving Consumer Goods (FMCG) products, rely heavily on a faster transport service, which involves a considerably higher transport cost. Additionally, the coefficient of TIME*LTSP is also statistically significant with a positive sign, implying that shippers with shorter length contracts (i.e. 3 years or less) are less sensitive to an increase in transport time than those with longer-term contracts.

The results of the CES3 model show that the mean and standard deviation coefficients of TIME, FREQ, RELIAB, and DAMG are statistically significant. All of the mean coefficients have the correct signs, which are negative for TIME and DAMG and positive for FREQ and RELIAB. The coefficient of COST also turns out to be statistically significant and it has the correct negative sign. The coefficient of ASCH is not statistically significant but the coefficient of ASCR is significant and has a negative sign. This implies that shippers in this group may equally prefer own-fleet and for-hire carries, but they inherently prefer rail less than these two options of road transport.

In terms of the interaction effects in the CES3 model, the coefficients of COST*LTSP, FREQ ${ }^{\star}$ NEMP, FREQ ${ }^{\star}$ EVOL, ASCH ${ }^{\star}$ NEMP, ASCH ${ }^{\star}$ NTRUCK, and ASCR ${ }^{\star}$ LTSP are all statistically significant. The negative coefficient of COST ${ }^{\star}$ LTSP suggests that shippers with short-term contracts are more sensitive to an increase in transport cost. The coefficient of FREQ ${ }^{\star}$ NEMP also has a negative sign, implying that SMEs are less sensitive to an increase in service frequency. The positive sign of the coefficient of FRE$\mathrm{Q}^{\star} \mathrm{EVOL}$ indicates that shippers that only transport their product for domestic consumption favour higher frequency services. Furthermore, all of the coefficients of $\mathrm{ASCH}^{\star} \mathrm{NEMP}, \mathrm{ASCH}{ }^{\star} \mathrm{NTRUCK}$, and

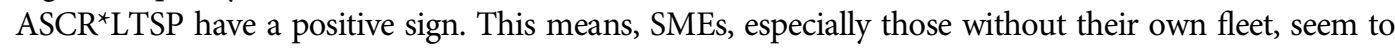
prefer for-hire carriers and shippers with a short-term contract seem to prefer rail.

The results of the CES4 model show that the coefficients of COST, TIME, and RELIAB are all statistically significant and have the correct signs (i.e. negative for COST and TIME and positive for RELIAB). The coefficients of three socio-economic attributes (i.e. EVOL, NTSP and LTSP) are also statistically significant. Furthermore, the coefficients of the interactions between COST and NEMP, COST and SLIFE, and FREQ and NTRUCK are also statistically significant. Taking the signs of these coefficients into account, the results suggest that shippers that transport short shelf life products are less sensitive to an increase in transport cost. Oddly, however, the results also suggest that SMEs are less sensitive to an increase in transport cost and shippers without their own fleet are more sensitive to an increase in service frequency. Furthermore, the coefficients of ASCH and ASCR are statistically significant and have a negative sign. The magnitude of the coefficient of ASCR is higher than that of ASCH. This shows that shippers with short-haul and LCL operation prefer for-hire carriers rather than rail, and own-fleet carriers are preferred the most. The inherent preference of short-haul and LCL shippers is similar to what is found in short-haul and FCL shippers. 


\section{Policy implications}

Various policy scenarios were developed in favour of rail and sea transport (for CES1) and rail transport (for CES2, 3 and 4). Note that for CES1, the three competing modes were road, rail and sea transport whereas for CES2, 3 and 4 the computing modes were rail and road transport (owned versus for-hire carriers). The simulation results of policy scenarios will be presented and discussed below based on these competing modes. Note that modal shift due to various policy scenarios (implying changes in the specified attributes) was calculated using arc elasticities, following a procedure described in Hensher et al. (2005).

\subsection{Road versus rail versus sea}

Many countries are adopting policies to encourage a modal shift from road to sea and rail transport. Some transport policies are used by governments to directly or indirectly suppress the use of road transport. Examples of direct approaches are fuel taxes and road user charges whereas examples of indirect approaches are subsidising other transport mode alternatives (by rail or sea), such as in the case of the Marco Polo programme (European Executive Agency for Competitiveness and Innovation, 2009), and improving the infrastructure associated with the other alternatives of transport mode to reduce the total transport time and increase reliability.

The mixed-logit model estimated from the CES1 data (Table 3a) were used to estimate the change in mode choice for a change in one or more attributes. Shippers and freight brokers with the long-haul and FCL operation seem to favour sea transport. The predicted freight mode shares were $16.5 \%$ by road, $59.1 \%$ by sea and $24.4 \%$ by rail. These estimated shares are fairly well aligned with the results of earlier studies by Richard Paling Consulting (2008) and Rockpoint Corporate Finance (2009). The former estimated the mode shares as $12.4 \%$ by road, $56.8 \%$ by sea and $30.8 \%$ by rail whereas the latter estimated the mode shares as $19 \%, 38 \%$ and $43 \%$ by road, sea and rail in turn. Note that estimating mode shares is quite difficult, due to the large variations between sources of aggregate-level data. Note also that the mode shares for interisland freight movements are approximate, and were derived from the results of Richard Paling Consulting (2008) (i.e. the Origin-Destination Matrix) and Rockpoint Corporate Finance (2009).

Four hypothetical scenarios tested were in favour of a greater use of rail and/or sea were: (1) increasing the road transport cost; (2) decreasing sea and rail transport costs; (3) decreasing sea and rail transport time; and (4) increasing sea and rail transport reliability. Figure 2 shows the estimated mode shares due to the changes in the specified attributes $( \pm 5 \%-25 \%)$ for four different hypothetical scenarios.

The results show that increasing the road transport cost - for instance, an extra tax or increase in road user charges - yields the largest increase in the mode share for sea transport, and the largest decrease in the mode share for road transport. On the other hand, decreasing sea and rail costs - for instance, a subsidy - yields a larger increase in mode share for rail than for sea transport. Furthermore, decreasing the transport time of rail and sea transport brings about only small increases in their mode shares, and increasing reliability in rail and sea as a part of a long term policy (such as expanding railways and developing seaport) is expected to increase the mode share of only rail.

It is worth noting that the largest declines in the share of road transport happen mostly when the cost of road transport is increased. This suggests that road transport users are more sensitive to disincentives (i.e. 'sticks') than they are to incentives to switch to other modes (i.e. 'carrots').

\subsection{Road versus rail}

According to the Ministry of Transport (2012) domestic freight transport grew distinctly faster than real GDP from 1996 to 2006, with GDP increasing 33\% and freight increasing 55\% (tonne-km). Richard Paling Consulting (2008) indicated that domestic freight transport in New Zealand takes 


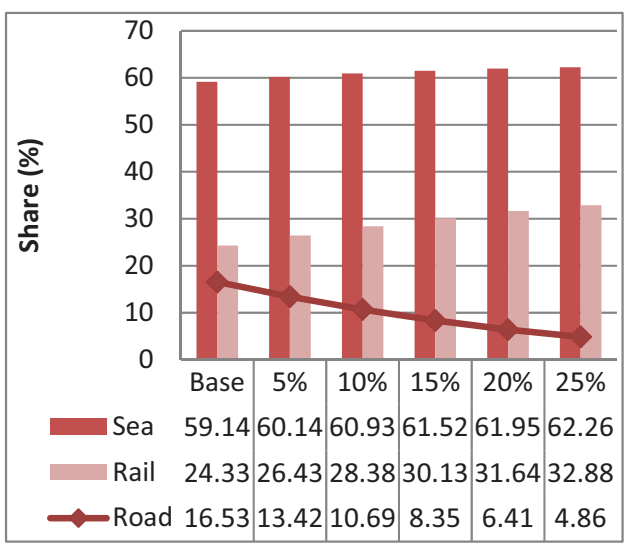

Scenario 1: Increase in road cost

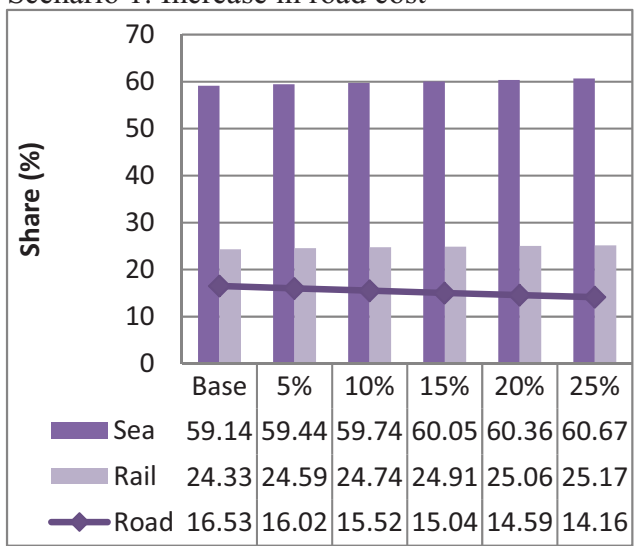

Scenario 3: Decrease in sea \& rail travel time

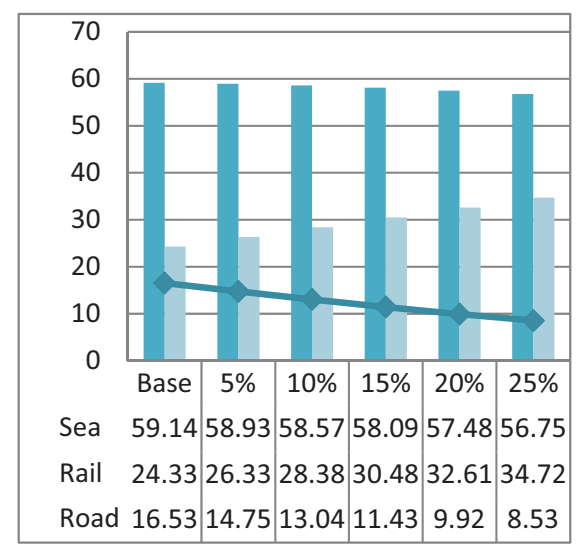

Scenario 2: Decrease in sea $\&$ rail cost

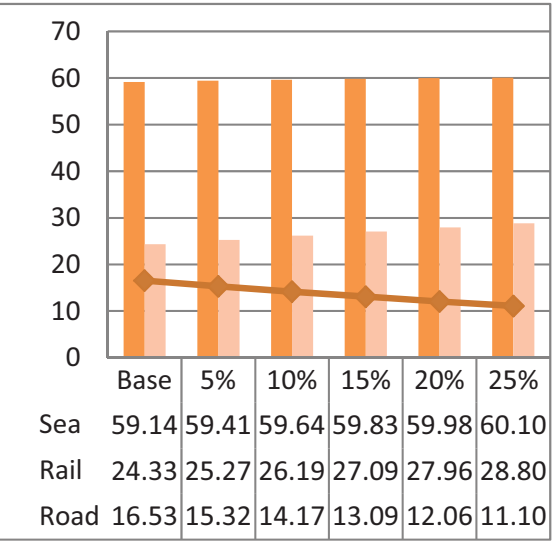

Scenario 4: Increase in sea $\&$ rail reliability

Figure 2. Policy implications for mode shares of road, sea and rail transports.

place mostly by road (92\% in terms of tonnes), leaving aside raw materials and bulk commodities (i.e. dairy, coal, petroleum, etc.), for which there is little competition between road and sea/rail. Most road shippers do have a choice between having their owned-fleets and hiring from for-hire carriers. However, little effort has been made to analyse the choice between these two road transport options.

The purpose of this section is to estimate the mode shares between rail and road transport, and to simultaneously compare between the two road transport options (i.e. owned-fleet and for-hire carrier). For this, the mixed-logit models estimated from the data of the short-haul and FCL shippers (CES2, Table 3b), the long-haul and LCL shippers (CES3, Table 3c), and the short-haul and LCL shippers (CES4, Table 3d) were used. Again, all of the tested scenarios were in favour of a greater use of rail: (1) increasing the road transport cost (both owned-fleet and for-hire carrier); (2) decreasing rail transport costs; (3) decreasing rail transport time; and (4) increasing rail transport reliability.

Using the CES2, 3 and 4 models, the base mode share for each operation type was estimated, and again incremental changes $( \pm 5 \%-25 \%)$ were applied. The results are shown in Figure 3.

As expected, the results show that road transport is the dominant transport mode choice for shippers in CES2, 3 and 4. In addition, owned-fleet is highly favoured over for-hire carriers for shorthauling. The calculated base shares for road transport for each operation type were $90.1 \%$ (CES2), 81.1\% (CES3) and 96.4\% (CES4). These values were much higher than the estimated base share (24\%) for the long-haul and FCL operation (CES1). 


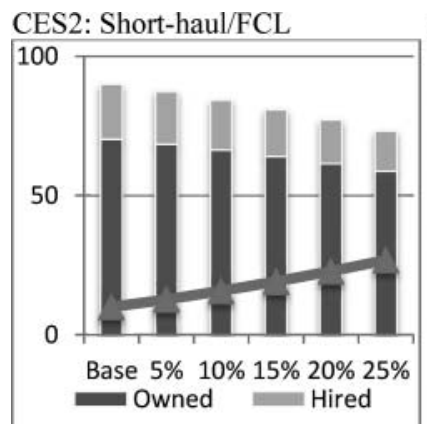

CES3: Long-haul/LCL

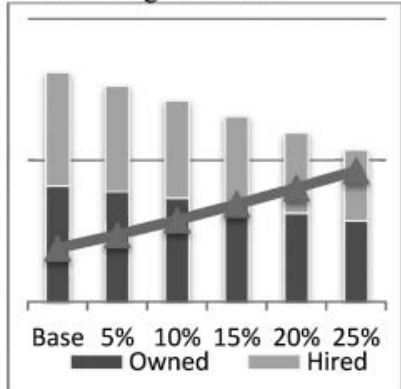

Scenario 1: Increase in road price

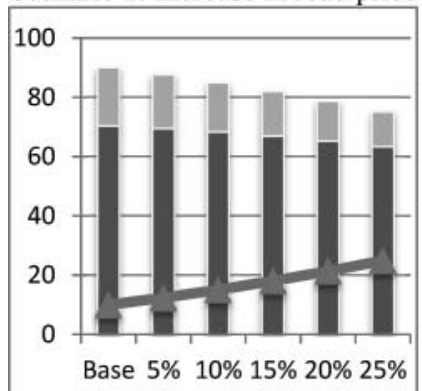

Scenario 2: Decrease in rail cost

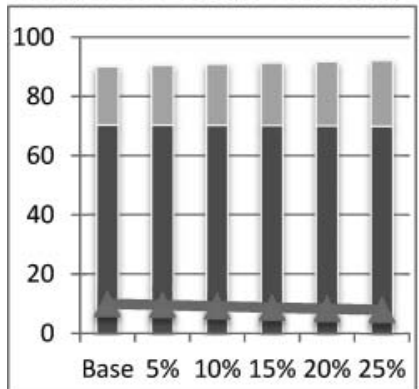

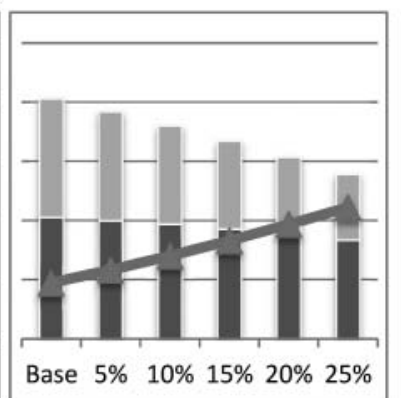

Base $5 \% \quad 10 \% 15 \% 20 \% 25 \%$

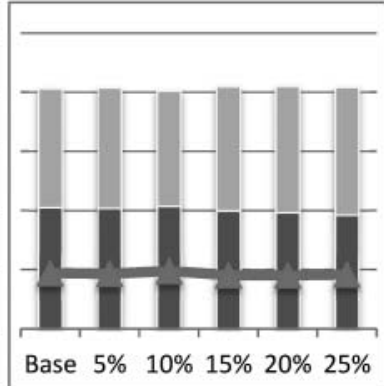

CES4: Short-haul/LCL
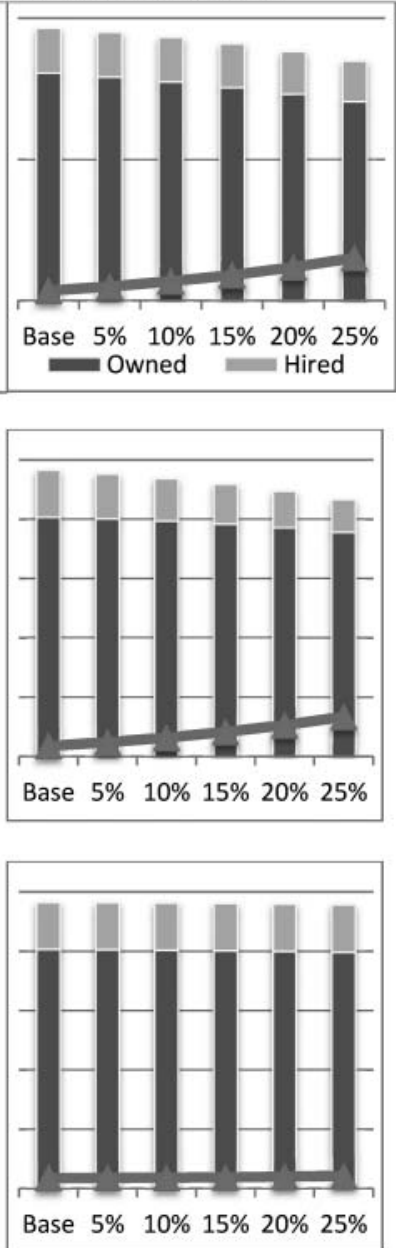

Scenario 3: Decrease in rail travel time
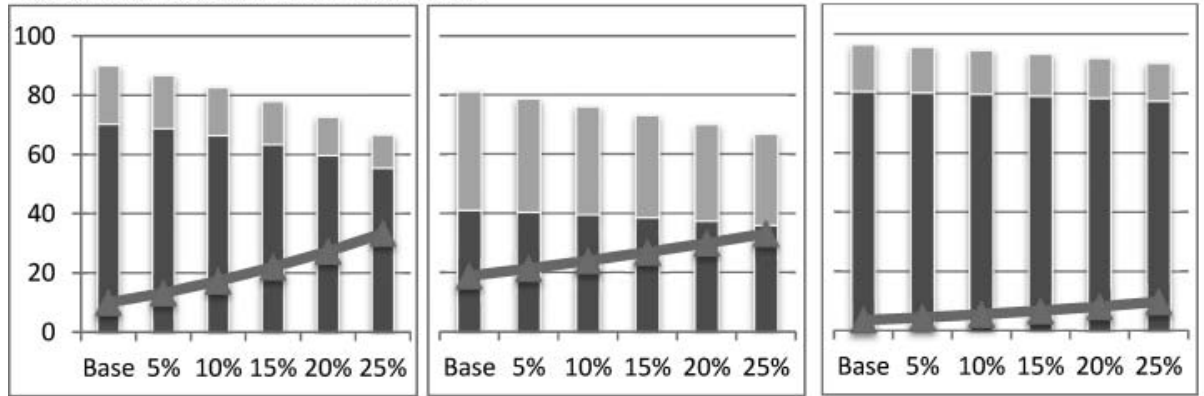

Scenario 4 : Increase in rail reliability

Figure 3. Policy implications for mode shares of rail and road (owned, hired) transports.

The calculated base share for rail for CES4 (the short-haul and LCL operation) was relatively low (i.e. 3.6\%). The calculated base share for rail for CES2 (i.e. the short-haul and FCL operation) was 9.9\% and it is slightly higher than for CES4. This result seems reasonable. Shippers that ship small volumes of cargo (such as in the case of CES4) were constrained by the minimum loading size threshold for rail. Additionally, rail charges FCL rates for LCL loads, making it unattractive for a 
LCL shipper to move cargo by rail, especially for those who need to transport goods only over short distances.

For the long-haul and LCL operation (CES3), the calculated share for rail was $18.9 \%$ and it is the highest share for rail amongst the four groups of shippers. Although, the mode share calculation shows that shippers in the three groups preferred road transport, the shares of owned-fleet and forhire carriers were different for the different transport distances and loads. The CES3 shippers appear to prefer for-hire carriers more than the CES2 and CES4 shippers.

In terms of the policy scenarios, increasing road price, decreasing rail price and increasing rail reliability are expected to yield a substantial modal shift from road to rail, while reducing travel time does not seem to be as effective. In contrast, two pricing policies (increasing road price and decreasing rail price) are more attractive to the long-haul shippers than to the short-haul shippers, and this result is consistent with the results for CES1. The results for CES3 indicate that by increasing road price by $25 \%$, the rail share will increase by $27.4 \%$, with the share increase being 'captured' evenly from owned-fleet and for-hire carriers. If the rail price was reduced by $25 \%$, rail gains almost the same amount (about 25.5\%), with 67\% of the share increase being from the for-hire carriers. Decreasing the transport time by rail does not produce any noticeable changes in the modal shares of road and rail.

It is worth noting that the results of improving rail reliability (by 25\%) suggest that rail will obtain higher modal shares (33.4\% for CES2 and 33.2\% for CES3) than the base shares (9.9\% for CES2 and $18.9 \%$ for CES3). This is impressive, as applying the same policy to the long-haul and FCL shippers (CES1) yields only a $4.5 \%$ increase in the share of rail. Increasing rail reliability (by $25 \%$ ) also proved to be an attractive policy for the short-haul and LCL shippers (CES4), with the rail share increasing by $6.3 \%$, from the base share of $3.5 \%-9.8 \%$.

\section{Conclusions}

This study investigated factors that influence the freight transport decisions by New Zealand freight shippers and carriers, by developing and estimating choice models. These models were used to identify the possibility of a modal shift from road transport to rail or sea transport. The results show that important factors that affect the freight mode decision vary with the shipper's operation type. As a result, public policy makers should recognize that freight transport mode choices are the results of evaluating various transportation characteristics (i.e. rates, reliability, transit time, etc.), logistics characteristics (level of inventories, logistics facilities, etc.) and products characteristics (size, value, etc.). Accordingly, policy makers should take these factors into account when formulating and implementing an effective policy to solve transport problems caused by high dependency on road transport.

By applying different hypothetical policy scenarios, the results of this study suggest that modal shift can be achieved. Shippers with the long-haul and FCL operation (CES1) already tend to utilize sea transport (59.1\%) and rail (24.4\%). These figures still can be improved further by increasing the road transport cost, for instance, an extra tax or an increase in road user charges. Such an increase yields the largest increase in the mode share for rail, and the largest decrease in the mode share for road transport. Additionally, increasing the reliability of rail and sea transport as a part of a long term policy may increase the mode share of rail transport.

In contrast to the long-haul and FCL shippers in CES1 that favour sea transport, shippers with the short-haul and LCL (CES4) or FCL (CES2) operations and shippers with the long-haul and LCL operation (CES3) seem to be more in favour of road transport, with owned-fleet being more preferred than for-hire carriers for short-hauling. For shippers in CES2, 3 and 4, increasing road price, decreasing rail price and increasing rail reliability seem to be able to considerably shift the mode choice from road to rail. Policy to increase road price or decrease rail price will lead to an increased use of rail transport, especially for long-haul shippers. 
Accordingly, to promote sustainable freight mobility, one very obvious change that can influence shippers with different freight operations would be to increase the reliability of both the rail and sea freight transport services. Transport reliability is important for transport service users, since freight transport is an important part of the logistics task, especially with the just-in-time approach. Road transport operators, particularly for-hire carriers, are pushing for greater reliability so they can provide a better service in the transport market. There are many factors that can influence freight transport reliability, such as operational decisions and infrastructure capacity, and policy should address both potential areas for improvement.

\section{Disclosure statement}

No potential conflict of interest was reported by the authors.

\section{References}

Addelman, S. (1962). Orthogonal main-effect plans for asymmetrical factorial experiments. Technometrics : A Journal of Statistics for The Physical, Chemical, and Engineering Sciences, 4(1), 21-46. https://doi.org/10.2307/1266170

Ballou, R. H. (2004). Business logistics/supply chain management: Planning, organizing, and controlling the supply chain. Upper Saddle River, NJ: Pearson/Prentice Hall.

Bliemer, M. C. J., \& Rose, J. M. (2009). Designing stated choice experiments: State of the art. In R. Kitamura, T. Yoshii, \& T. Yamamoto (Eds.), The expanding sphere of travel behavior research: Selected papers from the 11th conference of the international association for travel behavior research. Bingley: Emerald Group Publishing.

Bliemer, M. C. J., Rose, J. M., \& Hensher, D. A. (2009). Efficient stated choice experiments for estimating nested logit models. Transportation Research Part B: Methodological, 43(1), 19-35. https://doi.org/10.1016/j.trb.2008.05.008

Bolland, J., Weir, D., \& Vincent, M. (2005). Development of a New Zealand national freight matrix (Research Report No. 283). Wellington: New Zealand Transport Agency. Retrieved fromhttps://www.nzta.govt.nz/resources/ research/reports/283/

ChoiceMetrics Pty. Ltd. (n.d.). (2017). Ngene. Retrieved from http://www.choice-metrics.com/features.html

Daughety, A. F. (1979). Freight transport demand revisited: A microeconomic view of multimodal, multicharacteristic service uncertainty and the demand for freight transport. Transportation Research Part B: Methodological, 13(4), 281-288. https://doi.org/10.1016/0191-2615(79)90020-1

Deloitte. (2014). National freight demand study. Wellington: Ministry of Transport. Retrieved fromhttp://www.trans port.govt.nz/research/nationalfreightdemandsstudy/

Eccleston, J. A., \& John, J. A. (1996). Orthogonal main effect plans for two and three factors in small blocks. Metrika, 43(1), 203-211. https://doi.org/10.1007/BF02613908

European Executive Agency for Competitiveness and Innovation. (2009). Lightening the load - Marco Polo leads the way (pp. 1-28). Luxembourg: Office for Official Publications of the European Communities. Retrieved fromhttps://www.scribd.com/document/28076106/LIGHTENING-THE-LOAD-MARCO-POLO-LEADS-THEWAY

Evers, P., Harper, D., \& Needham, P. (1996). The determinants of shipper perceptions of modes. Transportation Journal, 36(2), 13-25.

Fowkes, A. S., \& Tweddle, G. (1988). A computer guided stated preference experiment for freight mode choice. Proceedings of the 16th PTRC summer annual meeting, London, UK.

Gilmour, P. (1976). Some policy implications of subjective factors in the modal choice for freight movements. Logistics and Transportation Review, 12(1). Retrieved fromhttps://trid.trb.org/view.aspx?id=66484

Gunn, H. (2002). An overview of European national models. In P. L. Lundqvist \& P. L.-G. Mattsson (Eds.), National transport models (pp. 19-34). Berlin, Heidelberg: Springer. https://doi.org/10.1007/978-3-662-04853-5_2

Hanley, N., Mourato, S., \& Wright, R. E. (2001). Choice modelling approaches: A superior alternative for environmental valuation? Journal of Economic Surveys, 15(3), 435-462. https://doi.org/10.1111/1467-6419.00145

Hedayat, A., Sloane, N. J. A., \& Stufken, J. (1999). Orthogonal arrays: Theory and applications. New York, NY: Springer.

Hensher, D. A., \& Greene, W. H. (2003). The mixed logit model: The state of practice. Transportation, 30(2), 133-176. https://doi.org/10.1023/A:1022558715350

Hensher, D. A., Rose, J. M., \& Greene, W. H. (2005). Applied choice analysis: A primer. Cambridge, UK: Cambridge University Press.

Huber, J., \& Zwerina, K. (1996). The importance of utility balance in efficient choice designs. Journal of Marketing Research, 33(3), 307-317. 
Jiang, F., Johnson, P., \& Calzada, C. (1999). Freight demand characteristics and mode choice: An analysis of the results of modeling with disaggregate revealed preference data. Journal of Transportation and Statistics, 2(2), 149-158.

Kessels, R., Jones, B., \& Goos, P. (2011). Bayesian optimal designs for discrete choice experiments with partial profiles. Journal of Choice Modelling, 4(3), 52-74. https://doi.org/10.1016/S1755-5345(13)70042-3

Kim, H. C. (2014). Developing a mode choice model for New Zealand freight transportation. (Dissertation). University of Canterbury, Christchurch. Retrieved fromhttp://ir.canterbury.ac.nz:80/handle/10092/10031

Kim, H. C., \& Nicholson, A. (2013). Freight transport modal shift in NZ: Building understanding of shippers' mode choice based on RP/SP surveys. Presented at the IPENZ Transportation Group Conference, Dunedin, NZ.

Kim, H. C., Nicholson, A., \& Kusumastuti, D. (2014). Freight transport mode choice and mode shift in New Zealand: Findings of a revealed preference survey. In Sustainable logistics (Vol. 6, pp. 165-192). Emerald Group Publishing Limited. Retrieved fromhttp://www.emeraldinsight.com/doi/full/10.1108/S2044-994120140000006007

Kim, H. C., Nicholson, A., \& Kusumastuti, D. (2017). Analysing freight shippers' mode choice preference heterogeneity using latent class modelling. Transportation Research Procedia, 25, 1109-1125. https://doi.org/10.1016/j. trpro.2017.05.123

Lanz, B., \& Provins, A. (2012). D o status quo choices reflect preferences? Evidence from a discrete choice experiment in the context of water utilities' investment planning (CEPE Working paper series No. 12-87). Switzerland: Center for Energy Policy and Economics, ETH Zurich. Retrieved from http://econpapers.repec.org/paper/ceewpcepe/12-87. htm

McFadden, D., \& Train, K. (2000). Mixed MNL models for discrete response. Journal of Applied Econometrics, 15(5), 447-470. https://doi.org/10.1002/1099-1255(200009/10)15:5<447::AID-JAE570>3.0.CO;2-1

McGinnis, M. (1990). The relative importance of cost and service in freight transportation choice: Before and after deregulation. Transportation Journal, 30(1), 12-19.

Ministry of Transport. (2012). Connecting New Zealand. Wellington: Ministry of Transport. Retrieved fromhttp:// www.transport.govt.nz/ourwork/keystrategiesandplans/connectingnewzealand/

Murphy, P., \& Daley, J. (1994). Logistics issues in international sourcing: An exploratory study. International Journal of Purchasing and Materials Management, 30(2), 21-27. https://doi.org/10.1111/j.1745-493X.1994.tb00193.x

Murphy, P., \& Hall, P. (1995). The relative importance of cost and service in freight transportation choice before and after deregulation: An update. Transportation Journal, 35(1), 30-38.

Ortúzar, J. de D., \& Willumsen, L. G. (2001). Modelling transport (3rd ed.). New York, NY: Wiley.

Pacific Logistic Ltd. (2011). Understanding transport costs and charges: 2011 freight charge comparison report. Wellington: Ministry of Transport.

Rich, J., Holmblad, P. M., \& Hansen, C. O. (2009). A weighted logit freight mode-choice model. Transportation Research Part E: Logistics and Transportation Review, 45(6), 1006-1019. https://doi.org/10.1016/j.tre.2009.02.001

Richard Paling Consulting. (2008). National freight demands study. Wellington: Ministry of Transport. Retrieved fromhttp://www.transport.govt.nz/assets/Uploads/Research/Documents/National-Freight-Demand-Study-Mar2014.pdf

Rockpoint Corporate Finance. (2009). Coastal shipping and modal freight choice. Wellington: New Zealand Transport Agency.

Sándor, Z., \& Wedel, M. (2002). Profile construction in experimental choice designs for mixed logit models. Marketing Science, 21(4), 455-475.

Warwick Walbran Consulting. (2010). Gisborne to Napier coastal shipping study. Wellington: New Zealand Transport Agency. Retrieved fromhttp://nzta.govt.nz/resources/gisborne-to-napier-coastal-shipping-study/

Widlert, S., \& Bradley, M. (1992). Preferences for freight services in Sweden. Proceeding of WCTR conference, Lyon, France. 